\title{
Analytical Evaluation of Usability of Object Oriented Software System
}

\author{
Sanjay Kumar Dubey \\ Amity University \\ Sector-125, NOIDA \\ Uttar Pradesh, India
}

\author{
Prof. Ajay Rana \\ Phd,Amity University \\ Sector-125, NOIDA \\ Uttar Pradesh, India
}

\begin{abstract}
The usability plays an important role in success or failure of the quality of software system. Object-oriented technology showed its importance to develop usable and efficient software system. There is a lack of usability models based on objectoriented technology as well as few efforts have done to evaluate usability qualitatively. This paper proposes a usability model for object-oriented system and evaluates the qualitative nature of this model. Evaluation is done by using fuzzy evaluation and AHP method. Results show that the qualitative nature of proposed model is better than the existing usability model.
\end{abstract}

\section{General Terms}

Software Engineering

Keywords

Usability, AHP, Object-oriented, Model, Fuzzy

\section{INTRODUCTION}

Usability has been included as a factor in almost all quality model proposed so far. It is an important concept of software engineering which determines the usefulness of a software system. The usability helps to build an efficient and effective software system. There is a need to evaluate usability as it reduces cost and increases productivity. In the year 1993, Nielsen gave the definition of usability as, "Usability of a system is a multi-faceted and consists of five properties: easy to learn; efficient to use; easy to remember; low error rate; and meets user satisfaction [11]. The usability and its specification's measurement has been one of the aims of development of ISO 9241-11 [9]. They defined usability as, "The extent to which a product can be used by specified users to achieve specified goals with effectiveness, efficiency and satisfaction in a specified context of use". In software development environment, object-oriented is the mostly and popularly used concept. In context to this, experts have developed various design metrics systems to aid in keeping track of the status of software system. The software metric systems are well established concepts and are means for evaluating a developed product's usability. Chidamber and Kemerer [22] efforts have given a set of metrics to help in assessing the usefulness for managers and developers. These design metrics evaluates one of the major influence of quality i.e. design complexity of object- oriented systems [22]. The CK metric suite is related to the internal structural analysis of object-oriented components such as inheritance, coupling, cohesion, method invocation, and association [13], [21], [23]. A relationship has been established between the factors of usability and the design metric system that leads to the evaluation of software system's usability.

Usability depends on various factors, but due to imprecise concepts and linguistic term involved in usability concept, it is difficult to measure and quantify [6]. This paper evaluates the quality nature of two object-oriented usability models. Each of the factors identified is characterized by fuzzy aspect. It uses the AHP technique for the evaluation of the proposed model and the fuzzy Index method [5] for the analysis and comparative study of both the models. The result shows that qualitative nature of proposed object-oriented usability model is better than the existing model. Index system method uses bottom to top approach for the software elements. It begins by considering the simple measurable data and moves upward analyzing the software's usability.

\section{PROPOSED USABILITY MODEL}

Object-oriented development has proved its value for systems that must be maintained and modified [14]. On the basis of thorough and detail study of its literature and guidelines [2], we have included the factors as Effectiveness, Efficiency, Satisfaction, and Learnability [20]. These factors, taken for object-oriented system are briefly defined as:

\section{Effectiveness}

Effectiveness is defined as the accuracy and completeness with which users achieve specified goals [9]. The most common measure of effectiveness taken by usability practitioners is:

- $\quad$ the completion rate;

- the percentage of users who successfully complete the tasks;

- $\quad$ amount of the tasks completed successfully;

- number of errors;

- $\quad$ percentage of relevant functions used;

- $\quad$ percentage of task completed; and

- percentage number of errors.

\section{Efficiency}

It can be defined as the, "resources expended in relation to the accuracy and completeness with which users achieve specified goals" [9]. E. Chang and T. S. Dillon [24] described efficiency as a quality of the user interface, which characterizes how efficiently the user can complete his task. They defined efficiency in number of components as:

- number of goals/task not achieved;

- time taken for task completion;

- unproductive period; and

- $\quad$ percentage of task not completed. 


\section{Satisfaction}

Satisfaction depends upon the positive response of user's experience. Satisfaction means that the software system has been successful in meeting the user's expectations [3]. Satisfaction is defined in ISO 9241-11 in terms of "comfort and acceptability of use" [9]. According to D. Alonso-Rios et al. [12], subjective satisfaction is the capacity of the system to produce feelings of pleasure and interest in user. Questionnaires [25] are developed for satisfaction measurement that can be specified on a subjective rating scale such as:

- discomfort experienced;

- $\quad$ liking for the product;

- $\quad$ satisfaction with product use;

- acceptability of the workload when carrying out different tasks; and

the extent to which

\section{Learnability}

ISO 9126-1[10] defines learnability as the capability of the software sytem to enable the user to learn its application. It should help the user to rapidly get acquaintance with the system to get the work done. According to A. Anthony [26], "learnability requires attention to the needs of the novice and uninitiated users. The uninitiated user is one that has no previous experience with the software or similar software. Novice user has either had some experience with similar software or has limited experience with the software".

The above usability factors can be evaluated using the objectoriented metrics system [15]. Hence we can relate objectoriented metrics as the third level of the usability concept and the factors as second level

\section{METRICS USED FOR EVALUATING USABILITY}

The literature has provided with various metric suite which depends on the internal structural analysis of object-oriented components [13], [21], [23]. This paper uses Chidamber and Kemerer (CK) software metrics [4] have been used. These metrics are aimed at assessing the design of object-oriented system rather than implementation. This makes them more suited to object-oriented paradigm as object-oriented design puts great emphasis on the design phase of software system [7]. The $\mathrm{CK}$ metric suite consists of six design complexity metrics- WMC, DIT, NOC, CBO, RFC and LCOM. The CK metrics are briefly described as follows [4]:

\subsection{Weighted Methods per Class (WMC)}

It is a weighted sum of all the methods defined in a class. It measures the complexity of a class. It also predicts how much time and effort is required to develop and maintain the class. High WMC indicates greater complexity and hence low maintainability.

\subsection{Depth of Inheritance Tree (DIT)}

It is the length of the longest path from a given class to the root class in the inheritance hierarchy and is measured by the number of ancestor classes. So this metric calculates how far down a class is declared in the inheritance hierarchy. High DIT indicates greater design complexity and more fault-proneness.

\subsection{Coupling Between Objects (CBO)}

For a class, $\mathrm{CBO}$ is measured by counting the number of other classes to which it is coupled. Coupling is a measure of interdependence of two objects. Two classes are coupled if methods of one use methods and/or instance variables of the other. High CBO indicates complex design, decreases modularity, and complicates testing of the class.

\subsection{Response for a Class (RFC)}

It is the count of all the methods which can potentially be executed (directly or indirectly) in response to a message to an object of that class or by some method in the class. (This includes all methods accessible within class hierarchy). High RFC means more effort required for testing, greater design complexity and fault-proneness.

\subsection{Lack of Cohesion in Methods (LCOM)}

Lack of Cohesion in Methods (LCOM): It is the degree to which the methods in a class are related to one another. LCOM measures the dissimilarity of methods in a class by instance variable or attributes. Higher cohesive module leads to standalone, increases simplicity whereas, lower cohesion increases complexity errors.

\subsection{Number of Children (NOC)}

It is equal to the number of immediate child classes derived from a base class. High NOC means greater level of reuse, more effort required for testing, more complexity and faultproneness.

The values of all the above metrics are inversely proportional to the usability of a object-oriented system [19].

\section{METHODOLOGY}

This paper shows a qualitative analysis of the software systems by using index system and fuzzy evaluation matrix [5] based in the model shown in Fig.1. The detail literature and methodology is adopted from [27]

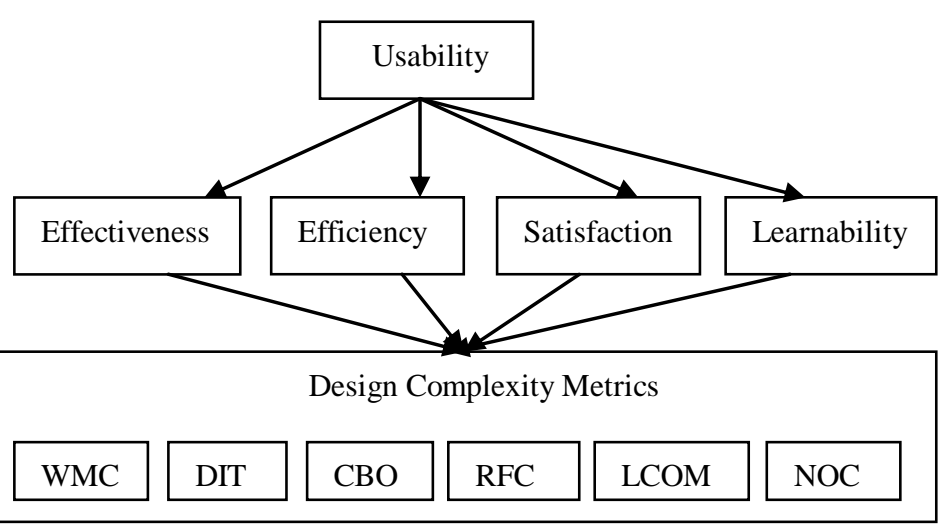

\section{Figure1. Proposed Usability Model}

\subsection{Analytical Hierarchy Process}

AHP method has been widely used in the decision making application in various fields such as government, business, industry, healthcare, and education. It provides the user with comprehensive and rational framework for such problems and quantifies the problem elements and relating it with the overall goal [18]. It represents a complicated problem into a hierarchy, which incorporates all the factors of that problem. It is a systematic process which provides logical and organized form of problem representation [8].

The following steps are mentioned for the evaluation of model: The pairwise comparison method uses $A=$ [aij] matrix to represent the intensities of expert's preference between individual pairs of alternatives (Ai versus $A j$, for all $i, j=1$, $2, \ldots n)$. 
Determine the weight values for each factor and sub-factors of usability using AHP method [18] on the basis of the survey conducted for the factors as well as for sub-factors.

Now, the consistency Index (C.I.) consistency ratio (C.R.) was calculated for the verification of the comparison matrix. C.I. and C.R. can be formulated as follows where $\lambda$ max is mean of eigen values

$$
\text { C.I. }=\frac{\lambda \max -n}{n-1} ; \quad \text { C.R. }=\frac{\text { C.I. }}{\text { R.I }}
$$

Where, R.I. is the average consistency index over numerous C.I. random entries of the same order reciprocal matrices [18] If C.R $<0.1$, then Aij is acceptable and correct otherwise values are inconsistent and not acceptable.

\subsection{Fuzzy Evaluation Method}

The fuzzy evaluation technology is adopted from the fuzzy technique and is helpful in overcoming imprecision in inputs and outputs [5]. Also, it provides a more expert knowledge for model building. This can be extended to allow for fuzzy premises which are used to draw conclusion. The evaluation level is supposed to be $\mathrm{F}=\{\mathrm{F} 1, \mathrm{~F} 2, \mathrm{~F} 3, \mathrm{~F} 4\}=$ poor, fair, good, excellent $\}$. This paper adopts semi trapezoidal distribution and the trapezoidal distribution [5] in assessing membership functions. If the threshold of the index obtained through the expert method is (v1, v2, v3, v4, v5), then we can get the membership functions [5]. The T1, T2, T3, T4 evaluated for each v i.e.v1, v2, v3, v4, and v5 constructs the fuzzy evaluation matrix.

$$
\mathrm{T} 1(\mathrm{v})= \begin{cases}1 & \mathrm{v} 1 \leq \mathrm{v} \leq \mathrm{v} 2 \\ \frac{\mathrm{v}-\mathrm{m} 2}{\mathrm{v} 2-\mathrm{m} 2} & \mathrm{v} 1<\mathrm{v}<\mathrm{m} 2 \\ 0 & \text { else }\end{cases}
$$

$$
\mathrm{T} 4(\mathrm{v})= \begin{cases}1 & \mathrm{v} 4 \leq \mathrm{v} \leq \mathrm{v} 5 \\ \mathrm{v}-\mathrm{m} 3 & \mathrm{~m} 3<\mathrm{v}<\mathrm{v} 4 \\ \frac{\mathrm{v} 4-\mathrm{m} 3}{0} & \text { else }\end{cases}
$$

The threshold obtained through expert method is (v1, v2, v3, $\mathrm{v} 4, \mathrm{v} 5)=(0,0.5,0.75,0.9,1)$ and $(\mathrm{m} 1, \mathrm{~m} 2, \mathrm{~m} 3, \mathrm{~m} 4)=(0.25$, $0.625,0.825,0.95)$ which denotes the median of (v1, v2) (v2, $\mathrm{v} 3),(\mathrm{v} 3, \mathrm{v} 4)$ and (v4, v5) respectively.

\section{CASE STUDY}

A survey was conducted on the experts to get the comparison values based on the ISO-9241 [9]. They were asked to give preferences to the factors identified and their relationship with the sub factors keeping in mind the usability concept and CK metrics.

\subsection{Evaluation of Project1}

Among the different projects available we have considered an object-oriented project (named project1) java language [29]. The project 1 is about 'Web Chat'. The project was selected on the basis, that it lacks the feature of Learnabilty. This project does not contain any feature of 'help', 'wizard', 'next step prompt', 'documentation' that can aid in learnabilty. The project code was passed under the software tool 'analyst $4 \mathrm{j}$ ' [28] which gave the values of the CK metrics which was tested against the threshold values [16], [17] as mentioned in Table 1. The 0 represents Boolean value not in range and 1 represents Boolean value in range.

Table 1. Boolean values of the CK metrics

\begin{tabular}{|l|l|l|l|}
\hline $\begin{array}{l}\text { 3rd Level } \\
\text { Index }\end{array}$ & $\begin{array}{l}\text { Threshold } \\
{[\mathbf{1 6}],[\mathbf{1 7}]}\end{array}$ & Current & $\begin{array}{l}\text { Boolean } \\
\text { Value }\end{array}$ \\
\hline WMC & $0-20$ & 4 & 1 \\
\hline RFC & $50-100$ & 22.5 & 0 \\
\hline LCOM & $0-1$ & 0.73 & 1 \\
\hline DIT & $0-3$ & 1 & 1 \\
\hline NOC & $0-1$ & 0 & 1 \\
\hline CBO & $0-5$ & 12.5 & 0 \\
\hline
\end{tabular}

According to the survey conducted we calculate the mean [1] of the sample collected from the survey of each level index as shown in Table 2. 
Table 2. Pair-wise comparison on ISO 9241 model

\begin{tabular}{|c|c|c|c|c|}
\hline $2^{\text {nd }}$ Level Index & 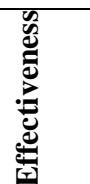 & 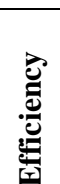 & 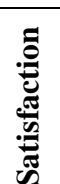 & 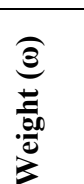 \\
\hline Effectiveness & 1 & 2.2 & 0.7 & 0.362 \\
\hline Efficiency & 0.455 & 1 & 0.5 & 0.192 \\
\hline Satisfaction & 1.429 & 2 & 1 & 0.446 \\
\hline
\end{tabular}

For above Table $2, \lambda \max =3.023 ;$ C.I. $=0.012 ;$ C.R. $=0.021$

Now, we calculate the weight of each CK metric under each usability factor Effectiveness, Efficiency, and Satisfaction. These are described in Table 3, 4, 5 respectively.

Table 3. Pair-wise comparison for Effectiveness

\begin{tabular}{|c|c|c|c|c|c|c|c|}
\hline $\begin{array}{l}3^{\text {rd }} \\
\text { Level }\end{array}$ & $\sum_{i}^{U}$ & U & 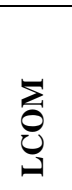 & $\overline{0}$ & $\begin{array}{l}\text { 乙 } \\
\text { 乙 }\end{array}$ & ְ) & 疍 \\
\hline WMC & 1 & 2.8 & $\begin{array}{l}0.73 \\
3\end{array}$ & $\begin{array}{l}2 . \\
4\end{array}$ & 3 & 2 & $\begin{array}{l}0.25 \\
5\end{array}$ \\
\hline RFC & 0.357 & 1 & $\begin{array}{l}0.36 \\
6\end{array}$ & $\begin{array}{l}2 . \\
2\end{array}$ & 1.7 & $\begin{array}{l}1.9 \\
33\end{array}$ & $\begin{array}{l}0.14 \\
3\end{array}$ \\
\hline LCOM & 1.364 & $\begin{array}{l}2.73 \\
2\end{array}$ & 1 & $\begin{array}{l}3 . \\
6\end{array}$ & 4.4 & $\begin{array}{l}1.8 \\
66\end{array}$ & $\begin{array}{l}0.31 \\
7\end{array}$ \\
\hline DIT & 0.417 & $\begin{array}{l}0.45 \\
5\end{array}$ & $\begin{array}{l}0.27 \\
7\end{array}$ & 1 & 2 & $\begin{array}{l}1.2 \\
9\end{array}$ & $\begin{array}{l}0.10 \\
4\end{array}$ \\
\hline $\mathrm{NOC}$ & 0.333 & $\begin{array}{l}0.58 \\
8\end{array}$ & $\begin{array}{l}0.22 \\
7\end{array}$ & $\begin{array}{l}0 . \\
5\end{array}$ & 1 & $\begin{array}{l}0.4 \\
67\end{array}$ & $\begin{array}{l}0.06 \\
8\end{array}$ \\
\hline $\mathrm{CBO}$ & 0.5 & $\begin{array}{l}0.51 \\
7\end{array}$ & $\begin{array}{l}0.77 \\
5\end{array}$ & $\begin{array}{l}0 . \\
53 \\
6\end{array}$ & $\begin{array}{l}0.77 \\
5\end{array}$ & $\begin{array}{l}2.1 \\
41\end{array}$ & $\begin{array}{l}0.11 \\
3\end{array}$ \\
\hline
\end{tabular}

For above Table 3, $\lambda \max =6.206 ;$ C.I. $=0.041 ;$ C.R. $=0.03$
Table 4. Pair-wise comparison for Efficiency

\begin{tabular}{|c|c|c|c|c|c|c|c|}
\hline $\begin{array}{l}3^{\text {rd }} \\
\text { Level }\end{array}$ & $\sum^{U}$ & U & 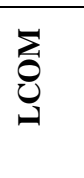 & $\bar{\theta}$ & $\begin{array}{l}\text { Ø } \\
\text { Z }\end{array}$ & O̊ & 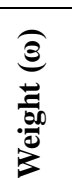 \\
\hline WMC & 1 & 1.3 & 0.5 & 3.4 & 2 & 3.4 & 0.23 \\
\hline RFC & 0.769 & 1 & 0.4 & 2 & 0.767 & 2.4 & 0.155 \\
\hline $\begin{array}{l}\text { LCO } \\
M\end{array}$ & 2 & 2 & 1 & 3 & 2.2 & 3 & 0.303 \\
\hline DIT & 0.294 & 0.5 & 0.333 & 1 & 0.333 & 1.7 & 0.081 \\
\hline NOC & 0.5 & 1.303 & 0.455 & 3 & 1 & 2 & 0.161 \\
\hline $\mathrm{CBO}$ & 0.294 & 0.417 & 0.333 & 0.588 & 0.5 & 1 & 0.07 \\
\hline
\end{tabular}

For above Table $4, \lambda \max =6.334 ;$ C.I. $=0.067 ;$ C.R. $=0.053$

Table 5. Pair-wise comparison for Satisfaction

\begin{tabular}{|c|c|c|c|c|c|c|c|}
\hline $\begin{array}{l}\text { 3rd } \\
\text { Level }\end{array}$ & $\sum_{z}^{U}$ & 琴 & 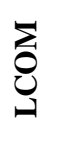 & $\overline{\bar{\theta}}$ & $\begin{array}{l}\text { Ŭ } \\
\text { Z }\end{array}$ & Oै & $\begin{array}{l}\vec{z} \\
\overrightarrow{000} \\
\overrightarrow{0} \\
\overrightarrow{3}\end{array}$ \\
\hline WMC & 1 & 2.2 & 3.2 & 2.4 & 9.5 & 2.4 & $\begin{array}{l}0.36 \\
2\end{array}$ \\
\hline RFC & 0.455 & 1 & 2.1 & 3 & 2.2 & 0.5 & $\begin{array}{l}0.16 \\
3\end{array}$ \\
\hline LCOM & 3.13 & 0.476 & 1 & 2.2 & 3 & $\begin{array}{l}0.36 \\
6\end{array}$ & $\begin{array}{l}0.11 \\
3\end{array}$ \\
\hline DIT & 0.417 & 0.333 & 0.455 & 1 & 3 & $\begin{array}{l}0.31 \\
6\end{array}$ & $\begin{array}{l}0.08 \\
4\end{array}$ \\
\hline NOC & 0.105 & 0.455 & 0.333 & $\begin{array}{l}0.3 \\
33\end{array}$ & 1 & $\begin{array}{l}0.26 \\
7\end{array}$ & $\begin{array}{l}0.04 \\
5\end{array}$ \\
\hline $\mathrm{CBO}$ & 0.417 & 2 & 2.732 & $\begin{array}{l}3.1 \\
64\end{array}$ & $\begin{array}{l}3.74 \\
5\end{array}$ & 1 & $\begin{array}{l}0.23 \\
3\end{array}$ \\
\hline
\end{tabular}

For above Table $5, \lambda \max =6.174 ;$ C.I. $=0.0347 ;$ C.R. $=0.028$

The values obtained are consistent as C.I. and C.R. are less than 0.1 as mentioned earlier.

The weight values obtained from analysis of the code is used to calculate the value vector $V_{\mathrm{T}}$ of $2^{\text {nd }}$ Level Index with the values of the $3^{\text {rd }}$ level Index W3 obtained from the survey report as in Fig. 2 


$$
\mathrm{W} 3=\left[\begin{array}{lllll}
.255 & .362 & .23 & 0 & \\
.143 & .163 & .155 & 0 & \\
.317 & .113 & .33 & 0 & \\
.104 & .084 & .081 & 0 & \\
.068 & .045 & .161 & 0 & \\
.113 & .233 & .070 & 0
\end{array}\right]
$$

Figure2. Weight values of the $3^{\text {rd }}$ Level Index excluding Learnability.

We can obtained $\mathrm{V}_{\mathrm{T}}$ as:

$\mathrm{V}_{\mathrm{T}}=\left[\begin{array}{lllll}1 & 0 & 11 & 1 & 0\end{array}\right] * \mathrm{~W} 3=\left[\begin{array}{lllll}0.744 & 0.604 & 0.755 & 0\end{array}\right]$

Now, we use the expert's formulae (1), (2), (3), (4) on the calculated $2^{\text {nd }}$ Level Index VT to obtain the fuzzy evaluation matrix R2. Thus we obtain the membership function which gives the matrix system for the same.

$$
\mathrm{R} 2=\left[\begin{array}{llll}
0 & 0.168 & 0 & 0 \\
1 & 1 & 0.667 & 0 \\
0.952 & 0 & 1 & 0 \\
0 & 0 & 0 & 0
\end{array}\right]
$$

For the evaluation of $1^{\text {st }}$ Level Index, we use the formula,

$\mathrm{U} 1=\mathrm{R} 2 * \mathrm{~W} 2$

Where U1 is the usability of Project1 and W2 is the matrix of the weight values of pair-wise comparison obtained by survey analysis.

$$
\begin{aligned}
& \text { Since W2 }=\left[\begin{array}{lllll}
0.362 & 0.192 & 0.446 & 0
\end{array}\right]^{\mathrm{T}} \\
& \text { Therefore U1 = R2 * W2 }=\left[\begin{array}{lllll}
0.032 & 0.851 & 0.791 & 0
\end{array}\right]^{\mathrm{T}}
\end{aligned}
$$

The membership function in poor case is 0.032 , for fair case is 0.851 , for good case is 0.791 , for excellent case is 0 . From the principal of maxima, we may conclude that the usability of Project 1 is of fair the category

\subsection{Evaluation of Project2}

Now, the second Project chosen is the advanced and upgraded version of the previous project. It is in java language and has been analyzed by the tool 'analyst $4 \mathrm{j}$ '. It is the 'Web Chat' developed in java, which incorporates all the factors of the object-oriented usability model [30].This system is not devoid of Learnability factor. This project is evaluated in the same way [5] as the previous project but here we have taken into consideration the weight values of Learnability factor. Therefore, we have new set of survey analysis for pair-wise comparison as shown in Table 6, 7, 8 .

\begin{tabular}{|c|c|c|c|c|c|}
\hline $2^{\text {nd }}$ Level Index & 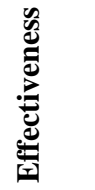 & 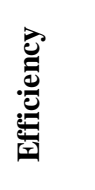 & 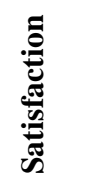 & 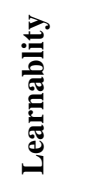 & $\begin{array}{l}\widehat{3} \\
\text { 音 } \\
\frac{500}{0} \\
3\end{array}$ \\
\hline Effectiveness & 1 & 2.3 & 0.4 & 1.667 & 0.252 \\
\hline Efficiency & 0.435 & 1 & 0.433 & 1.367 & 0.161 \\
\hline Satisfaction & 2.5 & 2.309 & 1 & 2.5 & 0.441 \\
\hline Learnability & 0.599 & 0.732 & 0.4 & 1 & 0.146 \\
\hline
\end{tabular}

Table 6. Boolean Values of CK Metrics

\begin{tabular}{|c|c|l|l|}
\hline $\begin{array}{c}\mathbf{3}^{\text {RD }} \begin{array}{c}\text { Level } \\
\text { Index }\end{array} \\
\text { WMC }\end{array}$ & $\begin{array}{c}\text { Threshold } \\
{[\mathbf{1 6}],[17]}\end{array}$ & $\begin{array}{c}\text { Current } \\
\text { Value }\end{array}$ & $\begin{array}{c}\text { Boolean } \\
\text { Value }\end{array}$ \\
\hline RFC & $0-20$ & 7.69 & 1 \\
\hline LCOM & $0-1$ & 0.37 & 1 \\
\hline DIT & $0-3$ & 1 & 1 \\
\hline NOC & $0-1$ & 0 & 1 \\
\hline CBO & $0-5$ & 4.23 & 1 \\
\hline
\end{tabular}

Table 7. Pair-wise comparison for proposed model

For above Table $7, \lambda \max =4.097 ;$ C.I. $=0.032 ;$ C.R. $=0.0359$

The survey for learnability with relation to CK metrics is added and the rest of the survey of CK metrics with respect to Effectiveness, Efficiency, and Learnability remains the same as for previous model. 
Table 8. Pair-wise comparison for Learnability

\begin{tabular}{|c|c|c|c|c|c|c|c|}
\hline $\begin{array}{c}\mathbf{3}^{\text {rd }} \\
\text { Level }\end{array}$ & $\sum^{U}$ & U & ְِ & 武 & $\begin{array}{l}\text { Oे } \\
\text { Z }\end{array}$ & Оి & 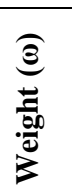 \\
\hline WMC & 1 & 3.8 & 2.2 & 1.8 & 1.367 & 1.367 & 0.264 \\
\hline RFC & $\begin{array}{l}0.26 \\
3\end{array}$ & 1 & $\begin{array}{l}0.43 \\
3\end{array}$ & 1.967 & 0.9 & 0.333 & 0.112 \\
\hline LCOM & $\begin{array}{l}0.45 \\
5\end{array}$ & 2.309 & 1 & 1.367 & 0.717 & 0.4 & 0.131 \\
\hline DIT & $\begin{array}{l}0.55 \\
6\end{array}$ & 0.508 & $\begin{array}{l}0.73 \\
2\end{array}$ & 1 & 1.1 & 0.683 & 0.111 \\
\hline $\mathrm{NOC}$ & $\begin{array}{l}0.73 \\
2\end{array}$ & 1.111 & $\begin{array}{l}1.39 \\
5\end{array}$ & 0.909 & 1 & 0.35 & 0.127 \\
\hline $\mathrm{CBO}$ & $\begin{array}{l}0.73 \\
2\end{array}$ & 3.003 & 2.5 & 1.464 & 2.857 & 1 & 0.255 \\
\hline
\end{tabular}

For above Table $7 \lambda \max =6.110 ;$ C.I $=0.022 ;$ C.R. $=0.017$

The W3 matrix obtained from the survey includes the weight values for learnability as in Fig. 3.

$$
\mathrm{W} 3=\left[\begin{array}{cccc}
.255 & .362 & .230 & .264 \\
.143 & .163 & .155 & .112 \\
.317 & .113 & .303 & .131 \\
.104 & .084 & .081 & .111 \\
.068 & .045 & .161 & .127 \\
.113 & .233 & .070 & .255
\end{array}\right]
$$

Figure3. Weight values of the $3^{\text {rd }}$ Level Index including Learnability.

Now we obtain $\mathrm{V}_{\mathrm{T}}$ as:

$\mathrm{V}_{\mathrm{T}}=\left[\begin{array}{llllll}1 & 0 & 1 & 1 & 1 & 1\end{array}\right] * \mathrm{~W} 3=\left[\begin{array}{lllll}0.857 & 0.837 & 0.845 & 0.888\end{array}\right]$

Using the expert's formula as done previously we obtain the fuzzy evaluation matrix R2.

$\mathrm{R} 2=\left[\begin{array}{lllll}0 & 0 & 0 & 0 & \\ 0 & 0 & 0 & 0 & \\ 1 & 1 & 1 & 1 & \\ 0.573 & 0.84 & 0.733 & 0.16\end{array}\right]$

For the evaluation of $1^{\text {st }}$ Level Index, we use the formula,

$$
\mathrm{U} 2=\mathrm{R} 2 * \mathrm{~W} 2
$$

Where U2 is the usability of Project 2 and W2 is the matrix of the weight values of pair-wise comparison obtained by survey analysis.

Since in this case W2 $=\left[\begin{array}{llll}0.252 & 0.162 & 0.441 & 0.146\end{array}\right]^{\mathrm{T}}$

Therefore $\mathrm{U} 2=\mathrm{R} * \mathrm{~W} 2=\left[\begin{array}{llll}0 & 0 & 1 & 0\end{array}\right]^{\mathrm{T}}$
The membership function in poor case is 0 , for fair case is 0 , for good case is 1 , for excellent case is 0 . From the principal of maxima, we may conclude that the usability of Project 2 is of good category.

\section{CONCLUSION}

This paper evaluated the usability of two object-oriented software systems. First software system was based on ISO9241 model and the second software system was based on the proposed model. The method of evaluation and comparative study has shown that the Project 2 with an additional Learnability feature is more usable as compared to Project 1 which was without Learnability feature. Therefore, we can conclude that a software system design features and attributes are measurable and they contribute in improving its efficiency and quality. The attention has to be paid to usability features which impact on the development process to produce highly usable software system interfaces. The result presented in this paper is qualitative. So, in future authors will evaluate usability quantitatively. Also, this kind of comparison can be carried out on real life projects from industry to evaluate their usability.

\section{REFERENCES}

[1] Kumar, A., Grover, P. S., Kumar, R. 2009 "A Quantitative Evaluation of Aspect-Oriented Software Quality Model: (AOSQUAMO)", ACM SIGSOFT, vol. 34, no. 5, pp. 1-9.

[2] Madan, A., Dubey, S. K. 2012 "Usability evaluation Methods: A Literature Review", International Journal of Engineering Science and Technology vol. 4, no.02, pp.590-599.

[3] Bevan, 1995 "Measuring usability as quality of use", Software Quality Journal vol.4, pp. 115-130.

[4] Chidamber, S. R., Kemerer, C. F., 1994 "A Metrics Suite for Object Oriented Design," IEEE Transactions on Software Engineering, vol. 20, no. 6, pp. 476-493.

[5] Jing, C., Xuyan, L. 2009 "Software Maintainability Metrics Based on the Index System and Fuzzy Method", $1^{\text {st }}$ International Conference on Science and Engineering, IEEE.

[6] Chang, E. and Dillon, T. S. 2006 "A Usability-Evaluation Metric Based on a Soft-Computing Approach", IEEE Transactions On System, Man and Cybernetics- Part A: Systems and Humans, vol. 36, no. 2.

[7] Dubey, S. K., Rana, A., 2010 "A Comprehensive Assessment of Object-Oriented Software Systems Using Metrics Approach", International Journal on Computer Science and Engineering, vol. 02, no. 08, pp. 2726-2730

[8] Coyle, G., 2004 Practical Strategy, Open Access Material. AHP, Pearson Education Limited, pp. 1-10.

[9] ISO 9241, 1998 "Ergonomics requirements for office work with visual display terminals (VDTs)" - Part 11: Guidance on usability.

[10] ISO/IEC 9126-1, 2001 "Institute of Electrical and Electronics Engineers, Part 1, 2, 3": Quality model.

[11] Nielsen, J. 1993 Usability Engineering. Academic press, San Diego, CA, 1993.

[12] Alonso, J. A., Lamata, T. 2005 "Consistency in the Analytic hierarchy Process: A New approach", Received: 30 October 2005, Revised: 15 May, 2006.

[13] Emam, K., Melo, W. and Machado, J. C. 2001 "The Prediction of Faulty Classes Using Object-Oriented Design Metrics", J.Systems and Software, vol. 56, pp. 6375. 
[14] Aggarwal, K. K., Singh, Y., Kaur, A. and Malhotra, R. 2006 "Empirical Study of Object-Oriented Metrics", Journal of Object technology, Vol. 5, No. 8, pp. 149-173.

[15] Rosenberg L. H. and Hyatt, L. 1995 "Software Quality Metrics for Object Oriented Environments," SATC NASA, Technical Report SATC-TR-95-1001.

[16] Selvarani, R., Gopalakrishnan Nair T. R., and Prasad, V. K. 2009 "Estimation of Defects Proneness Using Design complexity Measurement in Object-Oriented Software", International Conference on Signal Processing Systems, pp. 766- 770 .

[17] Shatnawi, R. 2006 "An Investigation of CK Metric Thresholds", ISSRE Supplementary Conference Proceedings, Chillarege Press.

[18] Saaty, T .L 1980 "The Analytic Hierarchy Process", McGraw Hill International.

[19] Dubey, S. K., Rana, A. 2010 "Assessment of Usability Metrics for Object-Oriented Software System", ACM SIGSOFT, vol. 35 , no. 6 , pp. 1-4.

[20] Dubey, S. K., Rana, A. and Sharma, A. 2012 "Usability Evaluation in Object Oriented software system using Fuzzy logic Approach", International Journal of Computer Application,vol. 43, No. 19, pp. 1-6.

[21] Subramanyam and Krishnan, R. 2003 "M.S. Empirical analysis of $\mathrm{CK}$ metrics for object-oriented design complexity: implications for software defects Software
Engineering”, IEEE Transactions on software Engineering, vol. 29, issue: 4, pp. 297- 310.

[22] Chidamber, S. and Kemerer, C. 1994 "A Metrics Suite for Object Oriented Design", IEEE Transactions on Software Engineering, vol. 20, no. 6, pp. 476-493.

[23] Basili, V. R. and Perricone, B. R. 1984 "Software Errors and Complexity", Comm. ACM, vol. 27, pp. 42-52.

[24] Chang, E. and Dillon T. S., "A Usability-Evaluation Metric Based on a Soft-Computing Approach", IEEE transaction on Systems, man, and Cybernetics-Part A Systems and Humans, Vol. 36, No. 2, March 2006.

[25] Porteous, M., Kirakowsky, J. and Corbett M., SUMI user handbook, Human Factors Research Group, University College Cork, 1993.

[26] Anthony, A., Software: a fine art, Jan 2004.

[27] Dubey S. K., Madan, A. and Rana A., "Qualitative Evaluation of Usability Model for Object-Oriented Software System, JCSE, Vol. 12, No. 2, April 2012.

[28] www.codeSWAT.com, Accessed date: $13^{\text {rd }}$ June'2012

[29] http://www.Planet-Source Code.com/vb/scripts/ShowCode.asp?txtCodeId=1893\&lng WId $=2$, Accessed date: $13^{\text {rd }}$ June'2012

[30] http://www.codeforge.com, Accessed date: $13^{\text {rd }}$ June'2012 